\title{
Evaluation and validation of an automatic jaw movement recorder (RumiWatch) for ingestive and rumination behaviors of dairy cows during grazing and supplementation
}

\author{
M. Rombach, ${ }^{*} \dagger$ A. Münger, ${ }^{*}$ J. Niederhauser, $\ddagger$ K.-H. Südekum, $†$ and F. Schori ${ }^{* 1}$ \\ *Agroscope, Tioleyre 4, 1725 Posieux, Switzerland \\ †Institute of Animal Science, University of Bonn, Endenicher Allee 15, 53115 Bonn, Germany \\ $\ddagger$ InnoClever $\mathrm{GmbH}$, Tiergartenstrasse 7, 4410 Liestal, Switzerland
}

\section{ABSTRACT}

Observation of ingestive and rumination behaviors of dairy cows may assist in detecting diseases, controlling reproductive status, and estimating intake. However, direct observation of cows on pasture is time consuming and can be difficult to realize. Consequently, different systems have been developed to automatically record behavioral characteristics; among them is the RumiWatch System (RWS; Itin and Hoch GmbH, Liestal, Switzerland). Until now, the RWS has not been thoroughly validated under grazing conditions. The aim of the current study was to validate the RWS, against direct observation, in measuring ingestive and rumination behaviors of dairy cows during grazing and supplementation in the barn. A further objective was to examine whether it is possible to refine the algorithm used by the evaluation software RumiWatch Converter 0.7.3.2 to improve the accuracy of the RWS. The data were collected from an experiment carried out with 18 lactating Holstein cows in a crossover block design including 3 treatments and 3 measuring periods. All cows grazed night and day, $19 \mathrm{~h} / \mathrm{d}$, and were either unsupplemented or supplemented, with chopped wholeplant corn silage, or chopped whole-plant corn silage mixed with a protein concentrate. During the measuring periods, cows were equipped with the RumiWatch Halter, and their ingestive and rumination behaviors were recorded concurrently by the RumiWatch Halter and by direct observation $(690 \times 10 \mathrm{~min})$. Comparison of concurrently measured data shows that the RWS detected jaw movements reliably, but classification errors occurred. A low relative prediction error of $\leq 0.10$ for the number of rumination boluses, rumination chews, and total eating chews was found. A high relative prediction error of $>0.10$ was found for the number of prehension

Received November 14, 2016.

Accepted November 16, 2017

${ }^{1}$ Corresponding author: fredy.schori@agroscope.admin.ch bites and time spent in prehension and eating. Both converter versions performed equally well in differentiating ingestive and rumination behaviors when cows were supplemented in the barn or when grazing and supplementation activities were combined. For grazing cows, with no supplementation, more reliable results for the total number of eating chews, rumination chews, prehension bites, and time spent in these activities were obtained, by using the RumiWatch Converter 0.7.3.11. In light of these findings, further research is warranted to improve the accuracy of the RWS and to allow a differentiation between mastication chews and prehension bites while eating.

Key words: automatic jaw movement recorder, dairy cow, grazing behavior, validation

\section{INTRODUCTION}

According to Penning and Rutter (2004), behavior exhibited by animals is an indication of the relationship between their internal state (e.g., nutritional requirements, health, or fertility) and their environment (e.g., feed offer, sward state, or climate). Thus, by monitoring behavioral characteristics, it may be possible to detect health disorders (González et al., 2008; Weary et al., 2009) and management deficiencies sooner. Consequently, reliable behavioral records are needed, and a robust relationship between the specific state and its associated behavioral characteristics must exist before valid statements about the animal's internal state can be made. Measuring the behavioral characteristics of dairy cows by direct observation, which is the current reference method, is time consuming and difficult for discrete behaviors such as biting or chewing without technical assistance. Tools to record behavioral characteristics for dairy cows exist, but their accuracy varies. In the past, to detect these behavioral characteristics, different sensing devices, such as electrical strain gauges (Beauchemin et al., 1989), silicon tubes packed with carbon granules (Rutter et al., 1997), acoustic 
monitoring systems (Ungar and Rutter, 2006), biaxial or triaxial accelerometers (Scheibe and Gromann, 2006; Oudshoorn et al., 2013), and pressure sensors (Nydegger et al., 2012) have been used. As mentioned by other investigators, some of these tools do not meet all requirements when it comes to measuring behavioral characteristics, were unsuitable for use in housing systems with head gates, or were unable to record single jaw movement (Nydegger and Keller, 2011; Zehner et al., 2012; Büchel and Sundrum, 2014).

The RumiWatch System (RWS), built in a cow halter, uses data gathered by a pressure sensor in combination with data collected by a triaxial accelerometer to detect different behavioral characteristics in dairy cows. Zehner et al. (2012) and Büchel (2014) reported that the RWS is able to record individual animal behavior over several days with high precision. Although extensively used in several studies, the only widespread validations of the RWS, to our knowledge, were published by Zehner et al. (2012) and Ruuska et al. (2016) for barn-fed cows.

In view of the prospective intention of using the RWS to record the quantification of pasture intake by grazing dairy cows based on behavioral characteristics, the first step must be to validate the most recent version of the RWS for grazing cows, with and without supplementation in the barn. Thus, behavioral characteristics recorded with the RWS, such as bolus counts, chews per bolus, number of eating chews, prehension bites, number of rumination chews, and derived durations such as rumination time, prehension time, and eating time were compared with continuous direct observation. If necessary, the refinement of the actual converter's algorithm was a further aim to increase the accuracy of the RWS.

\section{MATERIALS AND METHODS}

\section{Experimental Design, Animals, and Housing}

The study was carried out at the Agroscope experimental farm in Posieux, Switzerland (46 45 59.0" N, $7^{\circ} 6^{\prime} 17.2^{\prime \prime}$ E) between July 28 and September 27, 2014 (9 wk). All experimental procedures were in accordance with the Swiss guidelines for animal welfare and were approved (no. 2014_38_FR) by the Animal Care Committee of the Canton of Fribourg, Switzerland. Prior to selection of the cows, all possible cow candidates underwent a veterinary check-up. The experiment was performed as a crossover block design including 3 treatments and 3 periods. Each period lasted $21 \mathrm{~d}$, consisting of $2 \mathrm{wk}$ for adaptation and $1 \mathrm{wk}$ for measurements. The recordings for the validation of the RWS lasted from Monday to Friday during the second adaptation and the measurement weeks. Eighteen Holstein, or Red Holstein, dairy cows were used for the experiment; 12 of them were multiparous and 6 were primiparous. They were equally distributed in each of the 3 groups based on BW, ECM, and DIM. At the beginning of the experiment, the dairy cows had an average BW of 607 (SD 53) kg, were 122 (SD 45) DIM, had an average of 3.3 (SD 2.2) lactations, and produced 28.2 (SD 5.2) $\mathrm{kg}$ of milk/d.

The cows grazed during the day from 0730 to $1500 \mathrm{~h}$, and during the night from 1730 to $0500 \mathrm{~h}$ the following morning. During the remaining periods, the cows were housed in a freestall barn, were milked, were sampled, and 2 of the 3 experimental groups were supplemented at weighing troughs (Insentec B.V., Marknesse, the Netherlands) either with $10 \mathrm{~kg}$ of $\mathrm{DM} / \mathrm{d}$ of chopped whole-plant corn silage or with $8.2 \mathrm{~kg}$ of $\mathrm{DM} / \mathrm{d}$ of chopped whole-plant corn silage mixed with $1.8 \mathrm{~kg}$ of $\mathrm{DM} / \mathrm{d}$ of protein concentrate (supplemented cows). No supplementation was offered to the third group (unsupplemented cows), and by using the n-alkane double indicator method described by Mayes et al. (1986), individual herbage intake on pasture was estimated. Each cow served as its own control reference and underwent all 3 treatments. All cows from the 3 treatments grazed together in 0.3-ha paddocks. The paddocks were rotationally grazed by the cows for 1 to $3 \mathrm{~d}$ each, depending on pre- and postgrazing sward height (POSH). All sward heights were measured with an electronic rising plate meter (Jenquip, Feilding, New Zealand; 1 rising plate meter unit $=0.5 \mathrm{~cm}$ ), and the target for POSH was fixed at around 8 rising plate meter units (RPMU), corresponding to $4 \mathrm{~cm}$. The average pregrazing sward height was 15.5 (SD 3.9, $\mathrm{n}=26$ ) RPMU, corresponding to 1,287 (SD 696) $\mathrm{kg}$ of DM/ha above 8 RPMU. The average POSH was 7.6 (SD 0.9, $\mathrm{n}=26$ ) RPMU. The pastures were long established ( $>14 \mathrm{yr}$ ), composed of predominantly grasses $58 \%$ (SD 10\%) fresh matter (mainly Lolium perenne and Poa pratensis), herbs $29 \%$ (SD 14\%) fresh matter (mainly Taraxacum officinale and Plantago lanceolata), and legumes 13\% (SD 6\%) fresh matter (mainly Trifolium repens and T. pratense). On average, the experimental pastures were fertilized 3 times per year with a total of 125 (SD 25) kg/ha of ammonium nitrate $(27 \% \mathrm{~N}, 2.5 \% \mathrm{Mg}, 4.5 \% \mathrm{Ca}$, and $12 \% \mathrm{CaCO}_{3}$ ) and once with $45 \mathrm{~m}^{3} /$ ha of farm-produced manure (corresponding to approximately $36 \mathrm{~kg}$ of $\mathrm{N}$, $32 \mathrm{~kg}$ of $\mathrm{P}$, and $113 \mathrm{~kg}$ of $\mathrm{K}$ per ha). The chemical composition of the herbage, whole-plant corn silage, and protein supplement fed during the experimental periods is reported in Table 1. During the whole experiment, cows had free access to water troughs and to mineral licking buckets (Ca, P, Mg; UFA 999, UFA AG, 
Table 1. Average chemical composition of fresh herbage $(\mathrm{n}=50)$, whole-plant corn silage $(\mathrm{n}=3)$, and protein supplement samples $(\mathrm{n}=3)$

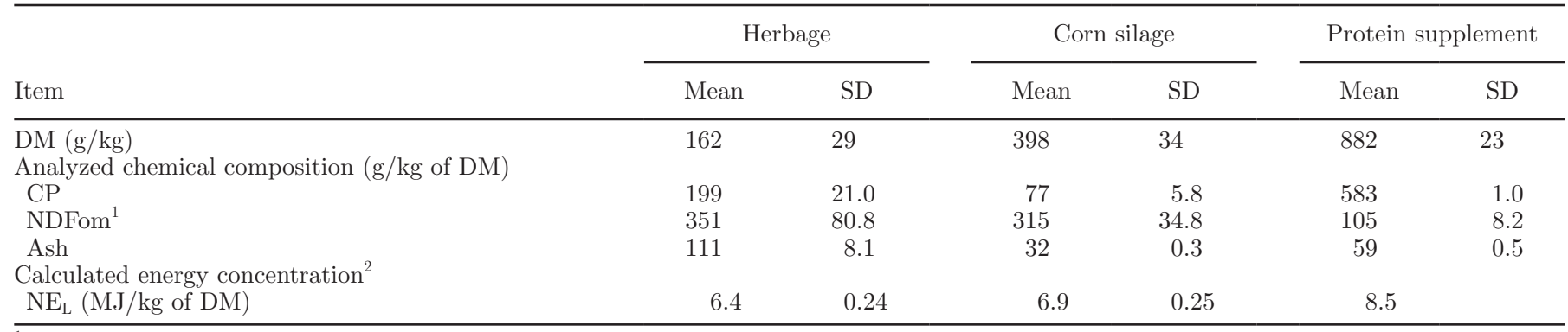

${ }^{1}$ NDFom $=$ NDF determined on an OM basis.

${ }^{2}$ According to Agroscope (2015).

Herzogenbuchsee, Switzerland). The ambient outdoor temperature and amount of rainfall were recorded daily by a nearby meteorological station (Meteo-Schweiz, Station, Posieux, Switzerland). During the experiment, the average temperature was $14.8^{\circ} \mathrm{C}$ (minimum $10.0^{\circ} \mathrm{C}$, maximum $19.9^{\circ} \mathrm{C}$ ), and it rained on 27 out of 63 experimental days, resulting in an average daily rainfall of 6 mm (minimum $0.1 \mathrm{~mm}$, maximum $11 \mathrm{~mm}$ ).

\section{Behavioral Measurements}

Behavioral characteristics were recorded with the RWS (Itin and Hoch GmbH, Liestal, Switzerland) consisting of the RumiWatch Halter (RWH) shown in Figure 1. The RWH combines 2 sensors, a pressure sensor connected to a tube filled with propylene glycol for the detection of pressure changes, caused by jaw movements, and a triaxial accelerometer to detect 3-dimensional movements of the head. The pressure sensor and the tube are placed in a belt on the nose bridge of the cow. The triaxial accelerometer, the data logger, and a secure digital memory card are located on the right belt ring, mounted in a waterproof plastic box. In another box on the left belt ring, the batteries are incorporated. Data collected by the pressure sensor and the triaxial accelerometer were recorded with a frequency of 10 $\mathrm{Hz}$ and saved on the secure digital memory card. The setup and the handling of the RWH are similar to that of a standard cow halter. To ensure the best possible detection of the jaw movements by the pressure sensor, the belt around the nose and the lower jaw left 3 to $5 \mathrm{~cm}$ of movement space to the nose bridge and was located between 11 and $16 \mathrm{~cm}$ behind the nasal tip. The recorded data were read out by the RumiWatch Manager (version 2.1.0.0, Itin and Hoch $\mathrm{GmbH}$ ) and processed through the evaluation software, called the RumiWatch Converter (C2, version 0.7.3.2, Itin and Hoch $\mathrm{GmbH}$ ). According to the manufacturer's information, $\mathrm{C} 2$ allows for differentiation between the fol- lowing behavioral characteristics based on RWH pressure data: number of rumination chews, bolus counts, chews per bolus, number of eating chews, drinking gulps, and other chews, along with the amount of time spent ruminating, eating, drinking, and other activities (Zehner et al., 2014). In our validation study, the focus was on the behavioral characteristics: chews per bolus, bolus counts, prehension bites, prehension time, number of eating chews, eating time, number of rumination chews, and rumination time. During the study, we developed a new RumiWatch Converter (C11, Itin and Hoch GmbH, Converter 0.7.3.11), which integrates the triaxial accelerometer data into the detection of ingestive and rumination behavioral characteristics. This converter was also validated for the same behavioral characteristics as $\mathrm{C} 2$.

To validate the RWS for recording ingestive and rumination behaviors, direct observations were performed. The direct observations and simultaneous RWS records were done on pasture for all cows (grazing cows) and additionally in the barn for supplemented cows (supplemented cows). A further evaluation was made with the in equal parts merged data sets of the grazing cows and the supplemented cows (supplemented grazing cows). Four days before the observations commenced, the cows were accustomed to the RWH. During an observation sequence, one cow was continuously observed for $10 \mathrm{~min}$. The cumulative duration of observation for each cow lasted $300 \mathrm{~min}$ on pasture and $100 \mathrm{~min}$ in the barn. The same observer performed all validation sequences; this resulted in 540 sequences (3 experimental periods $\times 10$ sequences $\times 18$ cows) for grazing cows and 150 sequences $(3$ periods $\times 5$ sequences $\times 10$ cows) for supplemented cows. As the stay in the barn was limited, only 10 supplemented cows were observed. The 10 observed cows out of 12 were selected randomly before each observation day. To detect potential diurnal differences in the quality of the raw data recorded with the RWH, the observations were conducted throughout 
Table 2. Definition of the behavioral characteristics used in the study

\begin{tabular}{|c|c|}
\hline Characteristic & Definition \\
\hline Prehension time & Time spent taking prehension bites, including interruptions between prehension bites as long as $5 \mathrm{~s}$. \\
\hline Mastication chews & $\begin{array}{l}\text { Chews performed throughout and shortly after eating for mechanical breakdown of the ingested material to finer } \\
\text { particles. No regurgitated material is used. }\end{array}$ \\
\hline Eating chews & Total number of prehension bites and mastication chews while eating. \\
\hline Eating time & Time spent for eating chews, including interruptions between eating chews up to $5 \mathrm{~s}$. \\
\hline Rumination chews & $\begin{array}{l}\text { Chews during rumination for mechanical breakdown of the regurgitated materials into finer particles using the } \\
\text { molars. }\end{array}$ \\
\hline Bolus count & A regurgitated mass of cud, which is swallowed again after chewing, counted when mass of cud is regurgitated. \\
\hline Chews per bolus & Chews performed during rumination between the regurgitation and swallowing of 1 bolus. \\
\hline
\end{tabular}

the day from 0530 to $2100 \mathrm{~h}$. The observed behavioral characteristics during these periods are precisely defined in Table 2. Using a tablet computer (Dell Venue 11 Pro, Dell GmbH, Geneva, Switzerland), the observed behaviors were recorded and saved in an Excel spreadsheet (Microsoft Excel 2010, Microsoft Deutschland GmbH, Hamburg, Germany). Specially developed macros linked to the buttons visible on the touchscreen counted and allocated the different behavioral elements

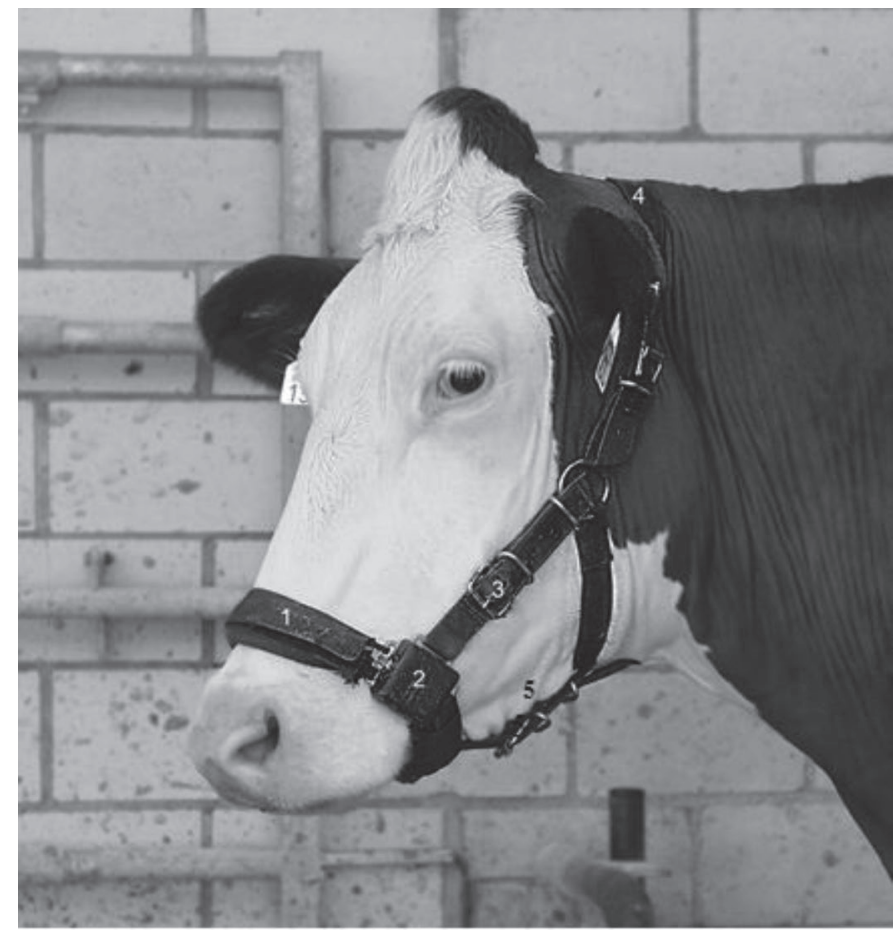

Figure 1. Red Holstein cow wearing a RumiWatch Halter version 6.0 (Itin and Hoch GmbH, Liestal, Switzerland). 1: Belt around the nose including a pouch with a propylene glycol-filled tube and the pressure sensor. 2: Waterproof plastic protection box (left side: battery; right side: triaxial-accelerometer, data logger, and secure digital memory card). 3, 4, 5: Adjustment buckles at the side, on the neck, and under the lower jaw, respectively. with the exact date and time in the Excel spreadsheet. To synchronize the timestamp of the aforementioned tablet computer and the RWS, the time of the RWS was set before each observation with the time of the tablet computer. Total number and duration of each observed behavioral characteristic was automatically summarized in a separate Excel spreadsheet. These summaries of the observed behavioral characteristics for the grazing, supplemented, and supplemented grazing cows were compared with simultaneously recorded RWH data processed with $\mathrm{C} 2$ or $\mathrm{C} 11$.

For problematic cases in relation to the eating chews, deviation $>40 \%$ between RWS records evaluated with $\mathrm{C} 2$ and observation, an additional, manual evaluation was completed. The manual evaluation was carried out by counting the amplitude peaks of obvious eating chews, shown in the RumiWatch Viewer (RWV, Itin and Hoch GmbH) and recorded by the RWH, with an amplitude higher than 7,500 Pa. The manually evaluated data were then compared with the results of the observation at the same time interval. For an accurate observation and a correct registration of behavioral characteristics, the observer was trained 2 wk before the experiment in detecting the different, defined behavioral characteristics, maintaining the correct distance to the cows, and handling the computer tablet as well as the aforementioned Excel spreadsheet. Finally, the coefficient of determination $\left(\mathrm{R}^{2}=0.97\right.$, good agreement) was checked between a sample ( $\mathrm{n}=$ 17) of manually counted eating chews based on RWV and the corresponding observed data (Figure 2).

\section{Laboratory Analysis}

After collection, fresh herbage and corn silage were frozen until lyophilization. Subsequently, all feeds, protein supplement included, were milled. Afterward, DM $\left(3 \mathrm{~h}\right.$ at $\left.105^{\circ} \mathrm{C}\right)$, ash (AOAC International, 1995, procedure 942.05), $\mathrm{N}$ (ISO, 2008; 16634-1, CP $=\mathrm{N} \times$ 6.25 ), and NDF determined on an OM basis (AOAC 
International, 1995, procedure 2002.4) content were analyzed.

\section{Calculations and Statistical Analysis}

The $\mathrm{NE}_{\mathrm{L}}$ concentrations of herbage, whole-plant corn silage, and protein supplement were calculated according to Agroscope (2015). The accuracy of the 2 converters in detecting the behavioral characteristics was assessed by the mean prediction error (MPE; Bibby and Toutenburg, 1977) and the limits of agreement (LoA; Carstensen et al., 2008). The MPE, bias, and variance components to estimate the LoA were obtained using R (R Core Team, 2015) by fitting linear mixed models with the function rlmer of the $\mathrm{R}$ package robustlmm (Koller, 2014), taking into account the nonnormal distribution of the residuals. In addition, relative prediction error (RPE) was calculated by dividing the MPE by the median of each variable. High accuracy of the measuring system is characterized by a low RPE (Delagarde and Lamberton, 2015). Furthermore, a small range between the lower control limit and the upper control limit indicates good evaluation accuracy. Moreover, the mean absolute deviation percent (MADP) of each behavioral characteristic was calculated as follows:

$$
\mathrm{MADP}=\frac{\sum_{k=1}^{N}\left|\mathrm{vis}_{k}-\mathrm{RW}_{k}\right|}{\sum_{k=1}^{N}\left|\operatorname{vis}_{k}\right|} \times 100 \%,
$$

where vis $=$ observed behavioral characteristic $\mathrm{x}$, observation $(k=1$ to $\mathrm{N})$, and RW = behavioral characteristic $\mathrm{x}$ measured automatically with the RWH and evaluated by $\mathrm{C} 2$ or $\mathrm{C} 11$, corresponding to observation $(k=1$ to $\mathrm{N})$. These variables were investigated for the 8 behavioral characteristics mentioned before.

\section{RESULTS}

Averaged across treatments, the cows consumed 10.6 (SD 2.98) $\mathrm{kg}$ of DM herbage/d and, if supplemented, on average 6.9 (SD 0.88) $\mathrm{kg}$ of DM supplemented feeds/d. They produced on average 23.3 (SD 4.6) $\mathrm{kg}$ of ECM/d.

The results of the comparison between $\mathrm{C} 2$ and the updated C11 against the observed behavioral characteristics are subsequently shown for the grazing, supplemented, and supplemented grazing cows.

\section{Validation for Supplemented Cows}

For supplemented cows, 150 observations and simultaneous records with RWH were carried out in total. Due to liquid leakage in the pressure sensor tubes, leading to sensitivity loss, only 121 (81\%) RWH records were used for further evaluation. The behaviors are mutually exclusive, so some of the variables did not yield values on each sequence; therefore, between 33 [1] and 58 observation sequences could be used to validate different behavioral characteristics in the barn. The

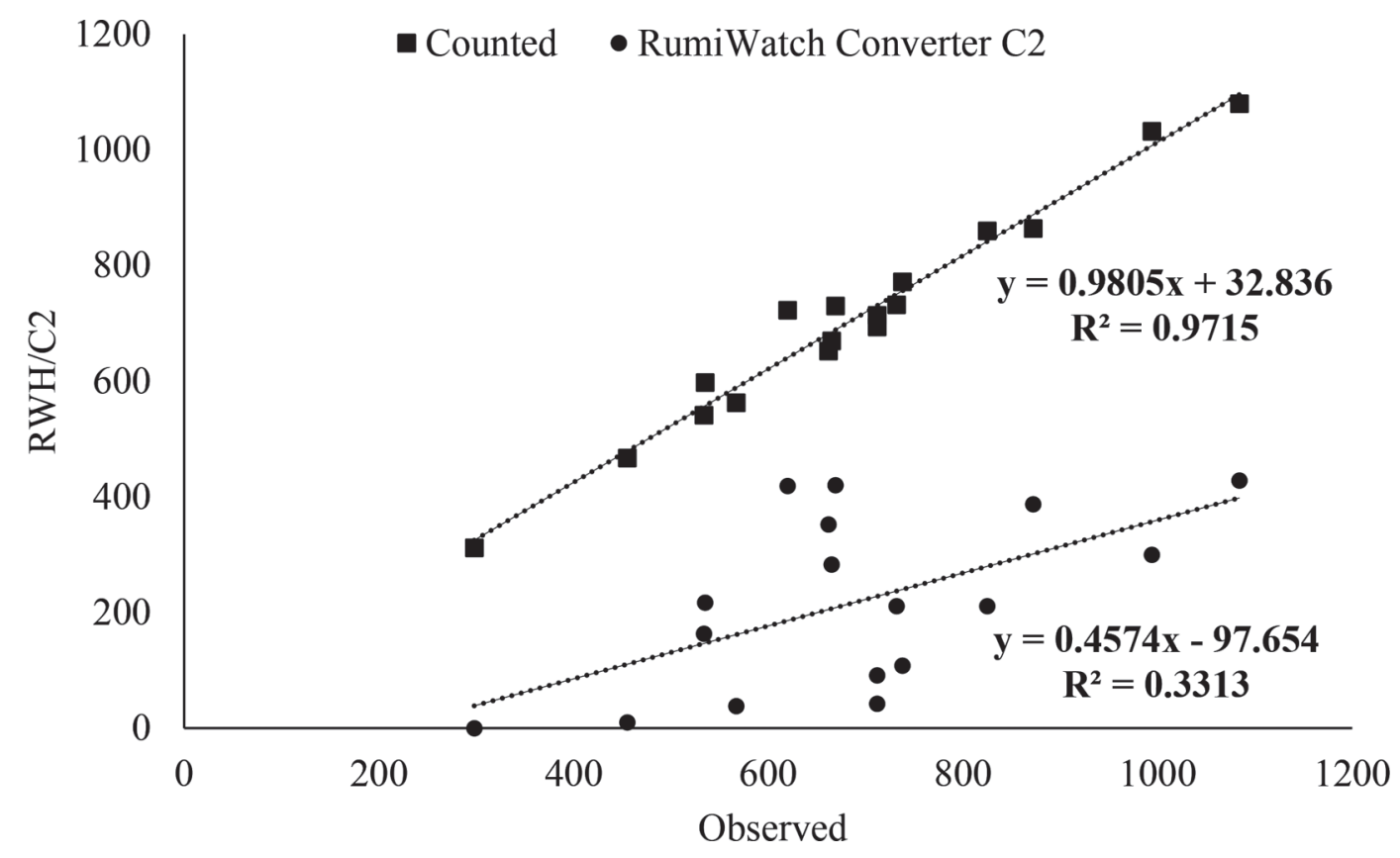

Figure 2. Relations of problematic cases between manually counted (based on RumiWatch Viewer; Itin and Hoch GmbH, Liestal, Switzerland) and automatically evaluated number of eating chews versus observed number of eating chews ( $\mathrm{n}=17$ observations). RWH $=\mathrm{RumiWatch}$ Halter. $\mathrm{C} 2=$ RumiWatch Converter 0.7.3.2. 
Table 3. Accuracy of RumiWatch (Itin and Hoch GmbH, Liestal, Switzerland) Converters 0.7.3.2 (Converter 2) and 0.7.3.11 (Converter 11) compared with direct observation in evaluating behavioral characteristics performed by the supplemented cows ${ }^{1}$

\begin{tabular}{|c|c|c|c|c|c|c|c|c|c|c|c|c|}
\hline \multirow[b]{2}{*}{ Item } & \multirow[b]{2}{*}{$\mathrm{n}$} & \multirow[b]{2}{*}{$\mathrm{V}^{2}$} & \multirow[b]{2}{*}{$\mathrm{RW}^{2}$} & \multirow[b]{2}{*}{ MADP } & \multirow[b]{2}{*}{ Bias $^{3}$} & \multirow[b]{2}{*}{$P$-value ${ }^{4}$} & \multicolumn{2}{|c|}{ LoA } & \multicolumn{2}{|c|}{$\begin{array}{l}\text { Regression from } \\
\text { direct to RW }\end{array}$} & \multirow[b]{2}{*}{ MPE } & \multirow[b]{2}{*}{$\mathrm{RPE}$} \\
\hline & & & & & & & LCL & UCL & $\begin{array}{l}\text { Intercept } \\
\text { estimate }\end{array}$ & $\begin{array}{l}\text { Slope } \\
\text { estimate }\end{array}$ & & \\
\hline \multicolumn{13}{|l|}{ Converter 2} \\
\hline Prehension bites ${ }^{5}$ & 33 & 332 & 546 & 127 & -88.9 & $<0.001$ & -525 & 348 & 18.8 & 1.59 & 164 & 0.49 \\
\hline Prehension time & 33 & 198 & 494 & 173 & -79.1 & 0.015 & -403 & 245 & 18.4 & 1.92 & 120 & 0.61 \\
\hline Rumination chews & 53 & 598 & 601 & 7 & -1.2 & 0.70 & -66 & 64 & 0.21 & 1.01 & 32.4 & 0.05 \\
\hline Rumination time & 53 & 600 & 598 & 6 & -1.6 & 0.70 & -88 & 85 & 1.59 & 1.00 & 43 & 0.07 \\
\hline Bolus count & 53 & 11 & 11 & 10 & 0.31 & 0.001 & -1.7 & 2.3 & -0.05 & 0.94 & 0.89 & 0.08 \\
\hline Chews per bolus & 53 & 51 & 54 & 23 & -0.8 & 0.60 & -33 & 32 & 0.04 & 1.03 & 16.6 & 0.32 \\
\hline \multicolumn{13}{|l|}{ Converter 11} \\
\hline Prehension bites & 33 & 332 & 473 & 137 & -97.5 & $<0.001$ & -543 & 348 & 27.9 & 1.57 & 174 & 0.52 \\
\hline Prehension time & 33 & 198 & 432 & 187 & -87.4 & $<0.001$ & -419 & 244 & 26.6 & 1.89 & 129 & 0.65 \\
\hline Chews per bolus & 53 & 51 & 55 & 23 & -0.2 & 0.90 & -32 & 31 & 0.50 & 1.00 & 15.8 & 0.29 \\
\hline
\end{tabular}

${ }^{1} \mathrm{n}=$ number of included records and observations. $\mathrm{V}=$ visual: median for number of, and time spent in, different behaviors observed directly ( $\mathrm{s} / 600 \mathrm{~s}$; bites or chews/10 min). RW = RumiWatch: median for amount of time spent in different behaviors recorded by the RW Halter ( $\mathrm{s} / 600$ $\mathrm{s}$; bites or chews $/ 10 \mathrm{~min}$ ). MADP = mean absolute deviation percent; LoA = limits of agreement; LCL $=$ lower confidence limit; UCL $=$ upper confidence limit; MPE = mean prediction error ( $\mathrm{s} / 600 \mathrm{~s}$; bites or chews/10 min); RPE = relative prediction error.

${ }^{2}$ The median is less sensitive to extreme values compared with the arithmetic mean.

${ }^{3}$ The bias is the fixed effect of the reference method (visual) compared with the instrumental method as estimated by the function rlmer of the $\mathrm{R}$ package robustlmm (Koller, 2014). It may be interpreted as the mean systematic error of the instrumental method.

${ }^{4} \mathrm{H}_{0}$ : bias $=0$.

${ }^{5}$ Out of 58 observation sequences with eating chews, only in 33 sequences prehension bites were observed. In the remaining 25 sequences, only few mastication chews were seen, leading to this apparently contradictory result.

sum of the observed number of prehension bites and mastication chews during eating were used as a reference for the number of eating chews.

Table 3 shows the validation results of the behavioral characteristics, evaluated using $\mathrm{C} 2$ and $\mathrm{C} 11$, for supplemented cows. The MADP between $\mathrm{C} 2$ and directly observed data were smaller for all behavioral characteristics, besides chews per bolus, when compared with the MADP of $\mathrm{C} 11$ and direct observation. Further, the slopes of the regression lines between $\mathrm{C} 2$ and the observed data for all behavioral characteristics, except prehension bites (about 1.6) and time (about 1.9), ranged between 0.93 and 1.03, and between 0.92 and 1.01, using C11. The RPE and the LoA for bolus counts, number of rumination chews, rumination time, prehension bites, prehension time, number of eating chews (Figure 3), and eating time were smaller when evaluated by $\mathrm{C} 2$ compared with $\mathrm{C} 11$, but not for chews per bolus. The MADP for chews per bolus was similar when data were evaluated either by $\mathrm{C} 11$ or $\mathrm{C} 2$. Bias between observations and data processed by $\mathrm{C} 2$ and
C11, respectively, were found for bolus counts $(P=$ 0.001 and $P<0.001$ ), number (both $P<0.001$ ), time of prehension $(P=0.015$ and $P<0.001)$, and eating time $(P<0.001$ and $P=0.006)$.

For supplemented cows, the comparison between $\mathrm{C} 2$ and $\mathrm{C} 11$ showed no differences $(P=0.54)$ for prehension bites, prehension time $(P=0.59)$, number of eating chews $(P=0.54)$, eating time $(P=0.59)$, number of rumination chews $(P=0.43)$, time spent for rumination $(P=0.57)$, bolus counts $(P=0.38)$, or chews per bolus $(P=0.86$; Table 4$)$. This indicates that both converters performed equally well for this condition.

\section{Validation for Grazing Cows}

For grazing cows, a total of 540 observations and simultaneous records using the RWH were collected. Due to the aforementioned technical problems, only 425 (79\%) RWH records could be used for further evaluation. The behaviors are mutually exclusive, so some of the variables did not yield values on each sequence; 


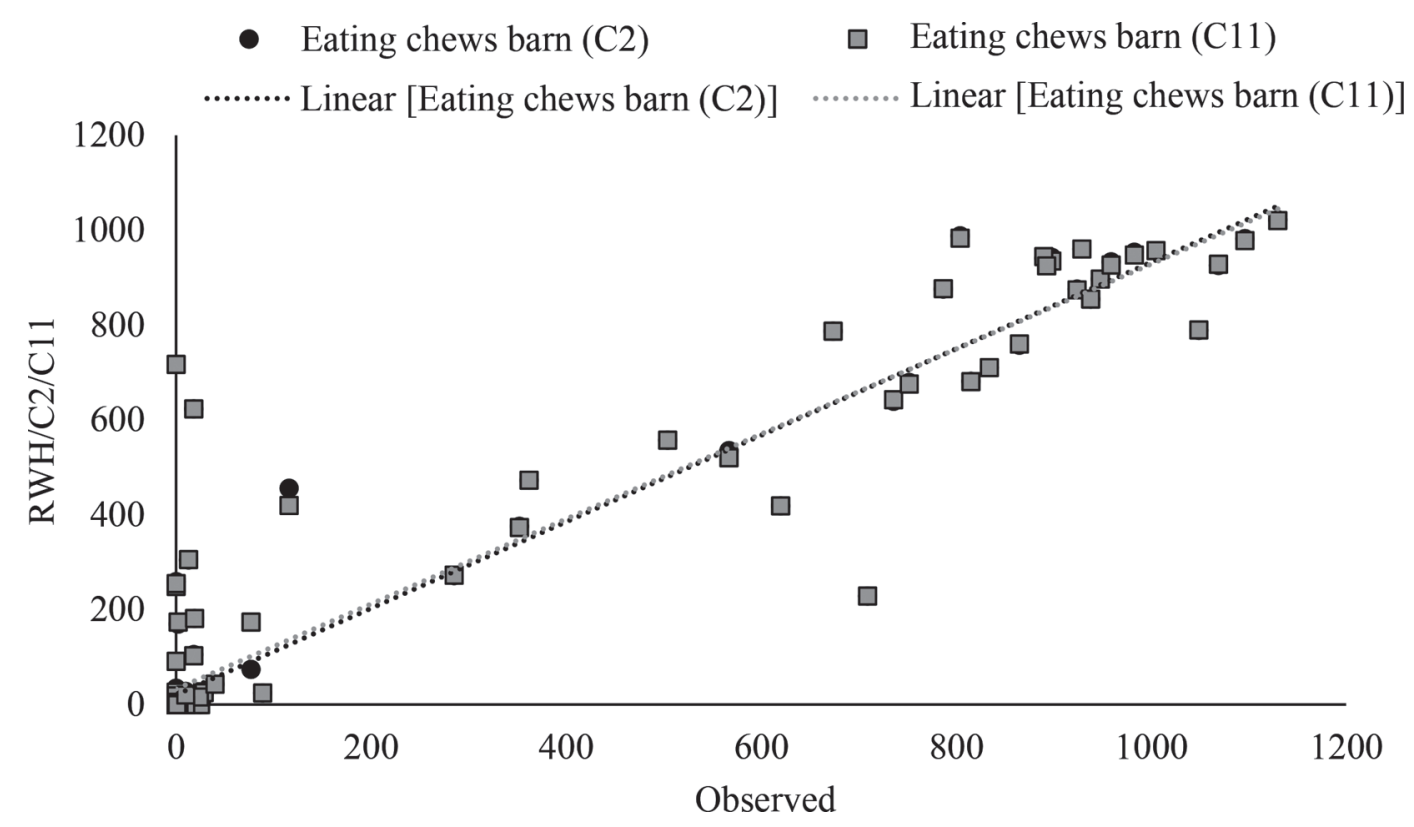

Figure 3. Relation of automatically evaluated [RumiWatch Converters 0.7.3.2 (C2) and 0.7.3.11 (C11); Itin and Hoch GmbH, Liestal, Switzerland] number of eating chews performed by supplemented cows versus observed number of eating chews $(\mathrm{n}=58$ observations). RWH $=$ RumiWatch Halter.

therefore, between 78 and 336 observation sequences could be used for validation. The sum of the observed number of prehension bites and mastication chews during eating were used as a reference for the number of eating chews.

Table 5 summarizes the validation results of $\mathrm{C} 2$ and C11 for grazing cows. The MADP between C11 and observations were smaller for all behavioral characteristics compared with $\mathrm{C} 2$. Furthermore, the slopes of the regression lines between $\mathrm{C} 11$ and the observed data for all behavioral characteristics ranged from 0.91 to 1.18, and from 0.89 to 1.15 for $\mathrm{C} 2$. When compared with direct observation, the RPE and the LoA for all behavioral characteristics were smaller when evaluated with C11. Bias between observation and data evaluated by C11 was found for bolus counts $(P<0.001)$, prehension bites $(P<0.001)$, prehension time $(P<0.001)$, number of eating chews $(P<0.001$; Figure 4$)$, and eating time $(P<0.001)$. For $\mathrm{C} 2$, differences with direct observation were found for prehension bites $(P<0.001)$, prehension time $(P=0.001)$, number of eating chews $(P<0.001)$, eating time $(P<0.001)$, number of rumination chews $(P=0.008)$, and rumination time $(P=0.005)$.

Comparing the processed results by $\mathrm{C} 2$ and $\mathrm{C} 11$ for grazing cows, differences were found for prehension bites $(P=0.009)$, prehension time $(P=0.008)$, number of eating chews $(P=0.009)$, eating time $(P=0.008)$, number of rumination chews $(P=0.009)$, and time spent for rumination $(P=0.008$; Table 4$)$.

\section{Validation for Supplemented Grazing Cows}

The validation of $\mathrm{C} 2$ and $\mathrm{C} 11$ for the supplemented grazing cows was performed by the aid of 242 observations and simultaneous records collected with the RWH. All 121 usable RWH records done for supplemented cows in the barn, and 121 records randomly selected from the 425 usable records for grazing cows, were included. As parts of the behavioral characteristics are mutually exclusive, between 74 and 155 observation sequences were used to validate the different characteristics. The sum of the observed number of prehension bites and mastication chews during eating were used as a reference for the number of eating chews.

Table 6 presents the validation results of the behavioral characteristics evaluated with $\mathrm{C} 2$ and $\mathrm{C} 11$ for the supplemented grazing cows. The MADP between $\mathrm{C} 2$ and the directly observed data were numerically smaller for prehension bites and prehension time when compared with C11. Concerning chews per bolus, number of rumination chews, and rumination time, MADP were numerically larger when raw data were evaluated by $\mathrm{C} 2$. Similar MADP between the 2 converter versions and direct observation were found for bolus counts, number of eating chews, and time spent eating. Furthermore, the slopes of the regression lines drawn between $\mathrm{C} 2$, C11 and observed data for all behavioral characteristics, except prehension bites (about 1.2) and time (about 1.3), ranged between 0.91 and 1.01. The 
RPE and the LoA for all behavioral characteristics were smaller between direct observation and when recorded data were evaluated using C11 compared with C2. Differences between observation and data evaluation by $\mathrm{C} 2$ and $\mathrm{C} 11$ were found for bolus counts $(P=0.004$ and $P<0.001$, respectively), prehension bites (both $P$ $<0.001$ ), prehension time (both $P<0.001$ ), number of eating chews $(P<0.001$ and $P=0.003$, respectively), and eating time $(P=0.001$ and $P<0.001$, respectively).

For the supplemented grazing cows, C2 and C11 showed no differences for prehension bites $(P=0.12)$, prehension time $(P=0.12)$, number of eating chews $(P=0.11)$, eating time $(P=0.11)$, number of rumination chews $(P=0.12)$, time spent for rumination $(P=$ $0.14)$, bolus counts $(P=0.14)$, and chews per bolus $(P$ $=0.39$; Table 4$)$. This indicates that both converters performed equally well.

Table 4. Comparison of RumiWatch Converters 0.7.3.2 and 0.7.3.11 (Itin and Hoch GmbH, Liestal, Switzerland) in evaluating different behavioral characteristics

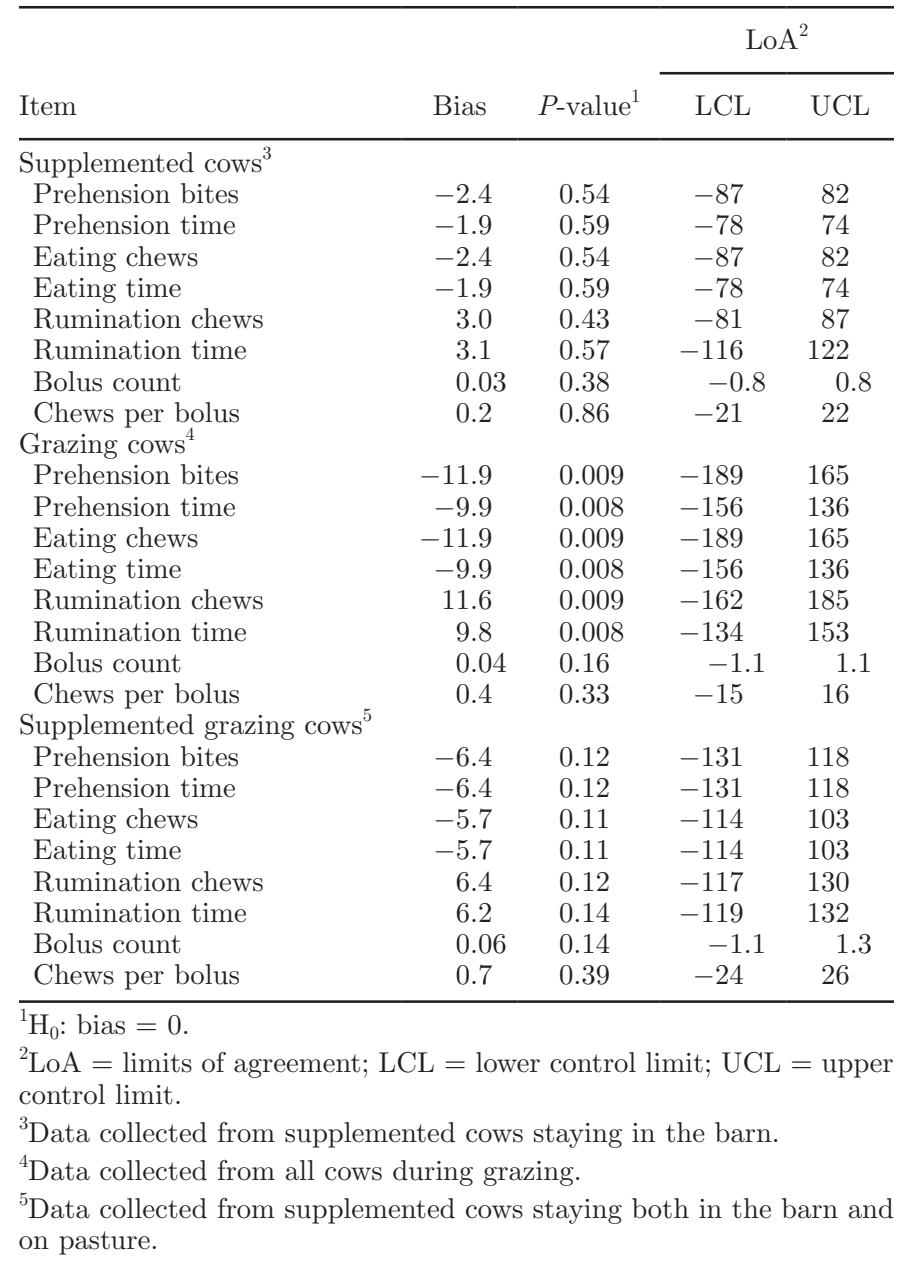

\section{Manual Evaluation of the RumiWatch Raw Data}

Figure 2 shows the relations between the manually counted, based on the RWV and automatically evaluated (C2) number of eating chews versus the directly observed ones for problematic cases $(n=17)$. Since problematic records were used, the coefficient of determination was low $\left(\mathrm{R}^{2}=0.33\right)$ between observed and automatically evaluated $(\mathrm{C} 2)$ eating chews, but between observed and manually counted eating chews it was high $\left(\mathrm{R}^{2}=0.97\right)$. This indicates that a high accordance exists between the observer and the records of the RWH in counting the number of eating chews.

\section{DISCUSSION}

\section{Data Collection and Procedural Considerations}

In our study, short, continuous, and direct observation sequences lasting 10 min were used for comparison with sensor-based data recordings and processing, because short sequences showed greater deviations than long ones (Bikker et al., 2014), and therefore more weak points are discovered. This was caused by the fact that the $\mathrm{C} 2$ and $\mathrm{C} 11$ algorithms were able to evaluate the raw data for 10-min summaries but were actually developed for measuring periods of $1 \mathrm{~h}$. However, it would be very difficult to observe and correctly log the cows' quickly changing behavioral sequences over a span of $1 \mathrm{~h}$. On the other hand, continuous observation allows the comparison of the number of single jaw movements or boluses, and consequently increases the accuracy of the validation when compared with instantaneous sampling; therefore, the former was preferred. Although continuous observation is the current reference method in recording how frequent and for how long an animal performs a behavior (Chen et al., 2016), loss of concentration and different recording practices between individuals can lead to errors. Penning (1983) stated that automatic recording systems are capable of recording behavior in far more detail than an observer in direct observation. This lies in their greater measuring capacity and, therefore, their greater measurement coverage during both day and night. Rutter et al. (1997) stated that the IGER Behavior Recorder shows the same accuracy as observers in recording foraging behavior, although there was a mean index of concordance of $91 \%$. The difference to $100 \%$ was attributed to the difficulties of the observer to correctly detect foraging behavior.

Data loss due to technical problems in our study amounted to $21 \%$. Unfortunately, few studies have reported the extent and causes of data loss that have occurred during their investigations, and they have not 


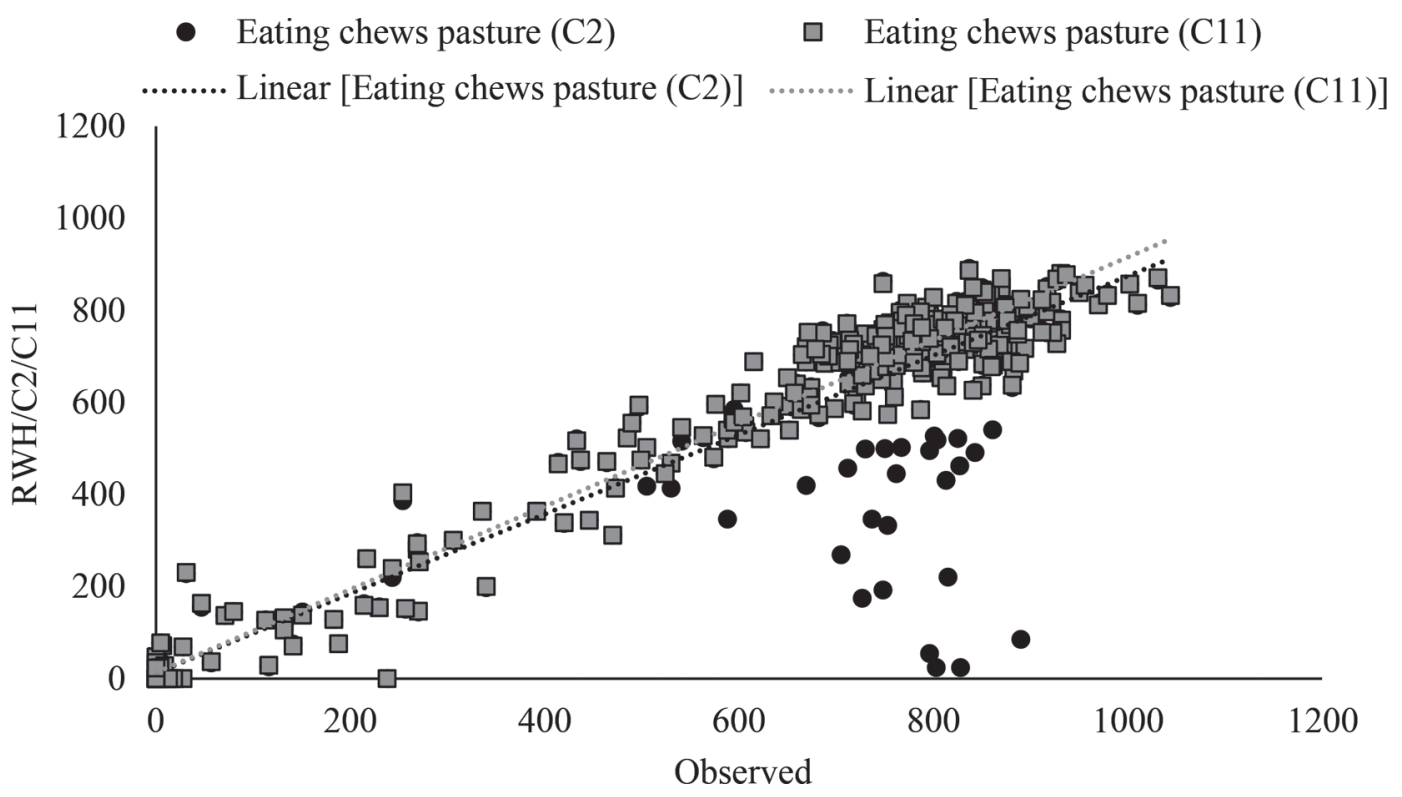

Figure 4. Relation of automatically evaluated [RumiWatch Converters 0.7.3.2 (C2) and 0.7.3.11 (C11); Itin and Hoch GmbH, Liestal, Switzerland] number of eating chews performed by grazing cows versus observed number of eating chews $(\mathrm{n}=336$ observations). RWH $=$ RumiWatch Halter.

Table 5. Accuracy of RumiWatch Converters 0.7.3.2 (Converter 2) and 0.7.3.11 (Converter 11) compared with direct observation in evaluating behavioral characteristics performed by the grazing cows ${ }^{1}$

\begin{tabular}{|c|c|c|c|c|c|c|c|c|c|c|c|c|}
\hline \multirow[b]{2}{*}{ Item } & \multirow[b]{2}{*}{$\mathrm{n}$} & \multirow[b]{2}{*}{$\mathrm{V}^{2}$} & \multirow[b]{2}{*}{$\mathrm{RW}^{2}$} & \multirow[b]{2}{*}{ MADP } & \multirow[b]{2}{*}{$\operatorname{Bias}^{3}$} & \multirow[b]{2}{*}{$P$-value ${ }^{4}$} & \multicolumn{2}{|c|}{ LoA } & \multicolumn{2}{|c|}{$\begin{array}{l}\text { Regression from } \\
\text { direct to RW }\end{array}$} & \multirow[b]{2}{*}{ MPE } & \multirow[b]{2}{*}{$\mathrm{RPE}$} \\
\hline & & & & & & & LCL & UCL & $\begin{array}{l}\text { Intercept } \\
\text { estimate }\end{array}$ & $\begin{array}{c}\text { Slope } \\
\text { estimate }\end{array}$ & & \\
\hline \multicolumn{13}{|l|}{ Converter 2} \\
\hline Prehension bites & 320 & 607 & 715 & 22 & -70.2 & $<0.001$ & -302 & 162 & 23.9 & 1.09 & 118 & 0.19 \\
\hline Prehension time & 320 & 448 & 598 & 36 & -98.4 & 0.001 & -320 & 123 & 42.7 & 1.15 & 109 & 0.24 \\
\hline Rumination chews & 78 & 577 & 583 & 33 & -12.3 & 0.008 & -192 & 168 & 15.8 & 0.99 & 93.8 & 0.16 \\
\hline Rumination time & 78 & 600 & 579 & 27 & -10.8 & 0.005 & -161 & 140 & 12.2 & 1.00 & 79.2 & 0.13 \\
\hline Bolus count & 78 & 11 & 10 & 16 & 0.05 & 0.21 & -1.5 & 1.6 & 0.02 & 0.94 & 0.77 & 0.07 \\
\hline Chews per bolus & 78 & 54 & 57 & 32 & -0.7 & 0.22 & -23 & 22 & 0.54 & 1.01 & 12.0 & 0.22 \\
\hline \multicolumn{13}{|l|}{ Converter 11} \\
\hline Prehension bites & 320 & 607 & 723 & 17 & -84.6 & $<0.001$ & -222 & 53 & 25.8 & 1.12 & 60.3 & 0.10 \\
\hline Prehension time & 320 & 448 & 599 & 27 & -111 & $<0.001$ & -271 & 48 & 42.6 & 1.18 & 71.7 & 0.16 \\
\hline Chews per bolus & 78 & 54 & 57 & 14 & -0.3 & 0.32 & -11 & 10 & 0.11 & 1.03 & 5.40 & 0.10 \\
\hline
\end{tabular}

${ }^{1} \mathrm{n}=$ number of included records and observations. $\mathrm{V}=$ visual: median for number of, and time spent in, different behaviors observed directly (s/600 s; bites or chews/10 min). RW = RumiWatch (Itin and Hoch GmbH, Liestal, Switzerland): median for amount of time spent in different behaviors recorded by the RW Halter (s/600 s; bites or chews/10 min). MADP = mean absolute deviation percent. LoA: limits of agreement. $\mathrm{LCL}=$ lower confidence limit. UCL $=$ upper confidence limit. MPE $=$ mean prediction error $(\mathrm{s} / 600 \mathrm{~s} ;$ bites or chews $/ 10 \mathrm{~min}) . \mathrm{RPE}=$ relative prediction error.

${ }^{2}$ The median is less sensitive to extreme values compared with the arithmetic mean.

${ }^{3}$ The bias is the fixed effect of the reference method (visual) compared with the instrumental method as estimated by the function rlmer of the $\mathrm{R}$ package robustlmm (Koller, 2014). It may be interpreted as the mean systematic error of the instrumental method.

${ }^{4} \mathrm{H}_{0}$ : bias $=0$. 
stated the exclusion criteria used to reject the data from further evaluation. Oudshoorn et al. (2013) mentioned a large number of missing values, due to lost data packages, when using di- and triaxial accelerometers. Chambers et al. (1981) recorded data loss of 9 to $24 \%$ when using a bitemeter, and between 9 and $15 \%$ by using a VibraCorder for the detection of ingestive behavior in sheep and cows; our proportion of data loss is thus similar to previous studies. However, a lower data loss would be desirable.

Regarding the primary results of problematic cases, the RWH recorded the number of eating chews accurately, but allocation by $\mathrm{C} 2$ was incorrect (Figure 2). Consequently, the MADP for the number of eating chews for poorly matching data pairs (observations vs. automatic records) was substantially reduced from 70 to $4 \%$ when evaluated manually. This finding led to the development of a new algorithm integrated in C11. In contrast to $\mathrm{C} 2$, C11 uses data taken with the pressure sensor and the triaxial accelerometer to differentiate between behavioral characteristics. The combination of data from both sensors for the evaluation of ingestive and rumination behaviors may increase the number of detectable behavioral characteristics and their accuracy. To our knowledge, until now, no other device has been able to offer the combination of a pressure sensor and a triaxial accelerometer to differentiate between ingestive and rumination behaviors. Instead, previous studies have used pressure sensors and triaxial accelerometers separately. Nonetheless, detection of single jaw movements during eating cannot currently be achieved with a triaxial accelerometer alone (Nydegger et al., 2011b).

Although C11 showed greater accuracy than C2 for several of the behavioral characteristics of grazing dairy cows, the development of RWS is not yet complete. With regard to the prospective estimation of the feed intake of grazing cows using the RWS, differentiation between mastication chews and prehension bites is important (Laca and WallisDeVries, 2000) and should therefore be integrated into the algorithm in future. Subsequently, the RWS will need to be validated, as it ought to be, whenever its hardware or software is modified, or when its area of application changes (Huber, 2013).

Table 6. Accuracy of RumiWatch Converters 0.7.3.2 (Converter 2) and 0.7.3.11 (Converter 11) compared with direct observation in evaluating behavioral characteristics performed by the supplemented grazing cows ${ }^{1}$

\begin{tabular}{|c|c|c|c|c|c|c|c|c|c|c|c|c|}
\hline \multirow[b]{2}{*}{ Item } & \multirow[b]{2}{*}{$\mathrm{n}$} & \multirow[b]{2}{*}{$\mathrm{V}^{2}$} & \multirow[b]{2}{*}{$\mathrm{RW}^{2}$} & \multirow[b]{2}{*}{ MADP } & \multirow[b]{2}{*}{$\operatorname{Bias}^{3}$} & \multirow[b]{2}{*}{$P$-value ${ }^{4}$} & \multicolumn{2}{|c|}{ LoA } & \multicolumn{2}{|c|}{$\begin{array}{l}\text { Regression from } \\
\text { direct to RW }\end{array}$} & \multirow[b]{2}{*}{ MPE } & \multirow[b]{2}{*}{$\mathrm{RPE}$} \\
\hline & & & & & & & LCL & UCL & $\begin{array}{l}\text { Intercept } \\
\text { estimate }\end{array}$ & $\begin{array}{c}\text { Slope } \\
\text { estimate }\end{array}$ & & \\
\hline \multicolumn{13}{|l|}{ Converter 2} \\
\hline Prehension bites & 121 & 593 & 691 & 39 & -75.6 & $<0.001$ & -423 & 272 & -36.8 & 1.22 & 153 & 0.26 \\
\hline Prehension time & 121 & 416 & 598 & 57 & -89.5 & $<0.001$ & -355 & 177 & -0.81 & 1.29 & 121 & 0.29 \\
\hline Rumination chews & 74 & 590 & 591 & 12 & -4.5 & 0.25 & -121 & 112 & 11.1 & 1.01 & 57.9 & 0.10 \\
\hline Rumination time & 74 & 599 & 598 & 10 & -3.7 & 0.34 & -120 & 112 & 6.97 & 1.00 & 56.8 & 0.09 \\
\hline Bolus count & 74 & 11 & 11 & 11 & 0.20 & 0.004 & -1.8 & 2.2 & 0.09 & 0.94 & 0.92 & 0.08 \\
\hline Chews per bolus & 74 & 51 & 55 & 28 & -1.1 & 0.34 & -35 & 33 & 1.30 & 1.01 & 16.7 & 0.33 \\
\hline \multicolumn{13}{|l|}{ Converter 11} \\
\hline Prehension bites & 121 & 593 & 697 & 40 & -88.1 & $<0.001$ & -421 & 245 & -18.5 & 1.23 & 145 & 0.24 \\
\hline Prehension time & 121 & 416 & 598 & 59 & -101 & $<0.001$ & -360 & 158 & 15.7 & 1.29 & 116 & 0.28 \\
\hline Chews per bolus & 74 & 51 & 55 & 23 & -0.2 & 0.78 & -23 & 22 & -0.51 & 1.01 & 11.8 & 0.23 \\
\hline
\end{tabular}

${ }^{1} \mathrm{n}=$ number of included records and observations. $\mathrm{V}=$ visual: median for number of, and time spent in, different behaviors observed directly (s/600 s; bites or chews $10 \mathrm{~min})$. RW = RumiWatch (Itin and Hoch GmbH, Liestal, Switzerland): median for amount of time spent in different behaviors recorded by the RW Halter (s/600 s; bites or chews/10 min). MADP = mean absolute deviation percent; LoA = limits of agreement; $\mathrm{LCL}=$ lower confidence limit; $\mathrm{UCL}=$ upper confidence limit; MPE = mean prediction error (s/600 s; bites or chews/10 min); RPE = relative prediction error.

${ }^{2}$ The median is less sensitive to extreme values compared with the arithmetic mean.

${ }^{3}$ The bias is the fixed effect of the reference method (visual) compared with the instrumental method as estimated by the function rlmer of the $\mathrm{R}$ package robustlmm (Koller, 2014). It may be interpreted as the mean systematic error of the instrumental method.

${ }^{4} \mathrm{H}_{0}$ : bias $=0$. 
Validation of RumiWatch Halter Data Evaluated Using C2 and C11

Prehension Bites and Time. Currently, it is possible to discriminate raw data measured by the RWH into rumination, eating, drinking, and other activities (Büchel, 2014; Ruuska et al., 2016), but C2 and C11 do not differentiate between mastication and true prehension bites while eating. Therefore, the number of prehension bites is overestimated for grazing cows and even more for supplemented cows. The higher overestimation of prehension bites for supplemented cows may be due to the higher share of mastication chews in the barn.

Eating Chews. The deviations (MADP) between the observed and automatically evaluated number of eating chews for supplemented cows (21 and 26\%) were higher than the previously obtained standard error of the mean (SEM) of $9 \%$ observed by Zehner et al. (2012). Similarly, Nydegger et al. (2011b) found a mean disagreement of $12 \%$ between automatically and manually evaluated raw data for the number of eating chews in housed dairy cows measured by the MSR behavior recorder. Differences in the accuracy of the sensors between the studies are difficult to interpret as measures of accuracy differ. A further tentative explanation for the differences between our study and that of Nydegger et al. (2011b) may be that individual behavioral characteristics contain individual animal specificities ( $\mathrm{Ny}-$ degger et al., 2011a). Therefore, the pressure signals may vary and the $\mathrm{C} 2$ or $\mathrm{C} 11$ algorithms may not have always been able to correctly allocate signals to a behavior. For grazing cows, the MADP of C11 for eating chews results shows that they correspond better to the observations than those of $\mathrm{C} 2(11$ vs. $14 \%)$ and are comparable to the aforementioned SEM of $9 \%$ for the number of eating chews in the barn reported by Zehner et al. (2012). The use of the pressure sensor and the triaxial accelerometer by C11 may explain the lower deviation. With $\mathrm{C} 11$, irregular chew frequencies detected by the pressure sensor coupled with increased acceleration in all 3 axes were associated with the number of eating chews. Gathering herbage with the tongue and ripping it off from the sward leads to upward (Phillips, 2002) and sideward movements of the head, which may explain these increased accelerations. González et al. (2015) also noted increased acceleration for the cattle's head during grazing, when a triaxial accelerometer was mounted on a collar under the neck. Based on low RPE of $\leq 0.10$ for 10 -min observation sequences, the accuracy of RWH coupled with C11 to detect the number of eating chews is sufficient for grazing cows.

Rumination Chews. Automatically recorded numbers of rumination chews for grazing cows and supple- mented cows showed a comparatively small deviation from the observation (MADP of about 10\%), except for grazing cows when raw data were evaluated by $\mathrm{C} 2$. This is consistent with the original approach to develop an automatic health-monitoring tool. The rumination process is essential for the fermentation and digestion of ingested feed (Murphy et al., 1983), and is influenced by different external conditions (Soriani et al., 2012); therefore, its monitoring may be a useful element when assessing the health status of ruminants. However, the deviations between the recorded and observed number of rumination chews in our study were higher than they were in Zehner et al. (2012), who reported a SEM of only $4 \%$. As previously explained, the longer observation sequences used by Zehner et al. (2012) may partly account for the lower deviations. The lowest MADP in our investigation was found for rumination chews when measured for grazing cows and evaluated with C11 (6\%). Similar results were obtained by Rutter et al. (1997), who determined a concordance index of 93\% for time spent ruminating by grazing dairy cows; this implies a deviation to direct observation of $7 \%$ of the IGER Behavior Recorder. Better differentiation between rumination and eating was achieved with C11 when data from the triaxial accelerometer were included. Signals of lower amplitude from a triaxial accelerometer during rumination compared with eating were already described by González et al. (2015). Based on a low RPE of $\leq 0.10$ for 10-min observation sequences, the accuracy of the RWH data processed with $\mathrm{C} 11$ in detecting the number of rumination chews is acceptable under different conditions.

Eating and Rumination Time. Estimations of time spent eating and ruminating generally exhibit a lower MADP when compared with counts of rumination and eating chews. Delagarde and Lamberton (2015) obtained with a uniaxial accelerometer (Lifecorder Plus) a lower RPE for the estimation of grazing time compared with our study (12 vs. $16 \%$ ), even if C11 was used. Blomberg (2011) reported a higher deviation for eating time measured by the HOBO logger (biaxial accelerometer) compared with our study [16 vs. $11 \%$ $(\mathrm{C} 2)$ and $7 \%(\mathrm{C} 11)]$. Additionally, the MADP for the rumination time of supplemented cows, measured with the RWH, was lower than the deviation from observation measured by the IGER Behavior Recorder $[6 \%$ (C2) and 7\% (C11) vs. 10\%; Kononoff et al., 2002]. The reason for the higher overall MADP for eating time $(15.7 \%)$ and lower overall MADP for rumination time (10.2\%) may be explained by the function modes of the C2 and C11 algorithms: time sequences, which were not assigned to rumination or other activities, were allocated as eating time and thus led to an overestimation of the latter. Furthermore, the same algorithm was 
used for the evaluation of 10-min and 1-h files, which also led to reduced accuracy. For example, rumination bouts have to last at least 3 min to be allocated as rumination by $\mathrm{C} 2$ and $\mathrm{C} 11$; otherwise, this time and the performed chews are classified as eating. The probability of including rumination bouts shorter than $3 \mathrm{~min}$ is higher in 10-min observation sequences compared with 1-h evaluation files. Consequently, the shorter length of evaluation files may partly explain greater deviations in our study, because, in most of the studies cited above, observation sequences of $1 \mathrm{~h}$ or longer were used.

Bolus Counts. The mean MADP compared with observation for bolus counts was $12 \%$, which is similar to the MADP of rumination chews. This is understandable, given that the $\mathrm{C} 2$ and $\mathrm{C} 11$ algorithms use the chewing interruption between 2 boluses to differentiate between rumination and eating. Each chewing interruption with a definite duration, starting with the first regurgitation of a bolus at the beginning of a rumination bout, is counted as 1 bolus. Based on low RPE of $\leq 0.10$ for 10 -min observation sequences, the precision of the RWH, coupled with $\mathrm{C} 11$ or $\mathrm{C} 2$ to detect the bolus counts, is sufficient under most conditions. Although bolus counts and rumination chews per bolus are important variables used to detect disorders in ruminants, these variables have not often been validated.

Chews Per Bolus. The mean MADP, compared with visual observation for chews per bolus, were higher ( 24 vs. $-0.2 \%$ ) than the mean deviation found by $\mathrm{Ny}$ degger et al. (2011b) who observed a deviation between automatically and manually evaluated raw data measured by the MSR behavior recorder. Moreover, Zehner et al. (2012) detected a lower SEM of 15\%. One reason for the higher deviations could be that the errors for the numbers of rumination chews and bolus counts are cumulated in their quotient, which could have led to a deviation of this magnitude.

\section{CONCLUSIONS}

Feeding behavior measured by the RWS and evaluated by 2 versions of the RumiWatch Converter (C2 and C11) shows variable results that were, in part, related to feeding conditions. Looking at the accuracy of the detected behavioral characteristics, performed by supplemented grazing or by supplemented cows, it did not matter which converter was used as the 2 versions performed equally well. However, more reliable results were obtained by using C11 for grazing cows, for total number of eating chews, number of rumination chews, prehension bites, and times spent engaging in these activities. Moreover, the RWS is a useful research tool for recording bolus counts, number of rumination chews, total number of eating chews, and time spent in rumination for grazing cows and supplemented grazing cows, when the raw data are processed by C11. For supplemented cows, the RWS is useful for recording bolus counts, rumination chews, and time. With regard to the prospective herbage intake estimation on pasture by the RWS, a new algorithm may be developed that reliably enables differentiation between mastication and prehension bites while eating. Furthermore, the improvement of the evaluation software is not yet finished; this, as well as validation of the system, should be continued in further studies.

\section{REFERENCES}

Agroscope. 2015. Fütterungsempfehlungen und Nährwerttabellen für Wiederkäuer (Feeding recommendations and nutrient tables for ruminants). Accessed May 6, 2015. http://www.agroscope.admin .ch/futtermitteldatenbank/04834/index.html?lang=de.

AOAC International. 1995. Official Methods of Analysis. 16th ed. AOAC International, Arlington, VA.

Beauchemin, K. A., S. Zelin, D. Genner, and J. G. Buchanan-Smith. 1989. An automatic system for quantification of eating and ruminating activities of dairy cattle housed in stalls. J. Dairy Sci. $72: 2746-2759$

Bibby, J., and H. Toutenburg. 1977. Prediction and Improved Estimation in Linear Models. John Wiley \& Sons, London. UK.

Bikker, J. P., H. van Laar, P. Rump, J. Doorenbos, K. van Meurs, G. M. Griffioen, and J. Dijkstra. 2014. Technical note: Evaluation of an ear-attached movement sensor to record cow feeding behavior and activity. J. Dairy Sci. 97:2974-2979.

Blomberg, K. 2011. Automatic registration of dairy cows grazing behaviour on pasture. $\mathrm{PhD}$ Thesis. Swedish University of Agricultural Sciences, Uppsala, Sweden.

Büchel, S. 2014. Sensor-based control of chewing and rumination behavior of dairy cows. PhD Thesis. Faculty of Organic Agricultural Sciences, University of Kassel, Kassel, Germany.

Büchel, S., and A. Sundrum. 2014. Technical note: Evaluation of a new system for measuring feeding behavior of dairy cows. Comput. Electron. Agric. 108:12-16.

Carstensen, B., J. Simpson, and L. C. Gurrin. 2008. Statistical models for assessing agreement in method comparison studies with replicate measurements. Int. J. Biostat. 4:16.

Chambers, A. R. M., J. Hodgson, and J. A. Milne. 1981. The development and use of equipment for the automatic recording of ingestive behaviour in sheep and cattle. Grass Forage Sci. 36:97-105.

Chen, J. M., K. E. Schütz, and C. B. Tucker. 2016. Technical note: Comparison of instantaneous sampling and continuous observation of dairy cattle behavior in freestall housing. J. Dairy Sci. 99:8341-8346.

Delagarde, R., and P. Lamberton. 2015. Daily grazing time of dairy cows is recorded accurately using the Lifecorder Plus device. Appl. Anim. Behav. Sci. 165:25-32.

González, L. A., G. J. Bishop-Hurley, R. N. Handcock, and C. Crossman. 2015. Behavioral classification of data from collars containing motion sensors in grazing cattle. Comput. Electron. Agric. 110:91-102.

González, L. A., B. J. Tolkamp, M. P. Coffey, A. Ferret, and I. Kyriazakis. 2008. Changes in feeding behavior as possible indicators for the automatic monitoring of health disorders in dairy cows. J. Dairy Sci. 91:1017-1028.

Huber, L. 2013. Validierung computergesteuerter Analysensysteme: ein Leitfaden für Praktiker. 1st ed. Springer, Berlin, Germany.

ISO (International Organization for Standardization). 2008. Food products-Determination of the total nitrogen content by combus- 
tion according to the Dumas principle and calculation of the crude protein content. ISO, Geneva, Switzerland.

Koller, M. 2014. Robustlmm: Robust Linear Mixed Effects Models. $\mathrm{R}$ package version 1.6. http://CRAN.R-project.org/package= robustlmm.

Kononoff, P. J., H. A. Lehman, and A. J. Heinrichs. 2002. Technical note: A comparison of methods used to measure eating and ruminating activity in confined dairy cattle. J. Dairy Sci. 85:1801-1803.

Laca, E., and M. WallisDeVries. 2000. Acoustic measurement of intake and grazing behaviour of cattle. Grass Forage Sci. 55:97-104.

Mayes, R. W., C. S. Lamb, and P. M. Colgrove. 1986. The use of dosed and herbage $\mathrm{n}$-alkanes as markers for the determination of herbage intake. J. Agric. Sci. 107:161-170.

Murphy, M., R. Baldwin, M. Ulyatt, and L. Koong. 1983. A quantitative analysis of rumination patterns. J. Anim. Sci. 56:1236-1240.

Nydegger, F., L. Gygax, and W. Egli. 2011a. Automatic measurement of rumination and feeding activity using a pressure sensor. Page 84 in Proc. Int. Conf. Agric. Eng. CIGR - AgEng, Clemont-Ferrand, France. Cemagraf, Antony Cedex, France.

Nydegger, F., L. Gygax, and W. Egli. 2011b. Automatisches Messen der Kaubewegungen bei Wiederkäuern mit Hilfe eines Drucksensors. Agrarforsch. Schweiz 2:60-65.

Nydegger, F., and M. Keller. 2011. Wiederkausensor für Milchkühe: automatisches Erfassen der Kau-und Fressaktivität zur Gesundheitsüberwachung. Forschungsanstalt Agroscope Reckenholz-Tänikon (ART), Switzerland.

Nydegger, F., A. Münger, and H. Frey. 2012. Research activities using the ART-MSR method of automatic recording and interpretation of rumination and feeding behavior. Pages C-0993 in Proc. Int. Conf. Agric. Eng. CIGR-AgEng, Valencia, Spain.

Oudshoorn, F. W., C. Cornou, A. L. F. Hellwing, H. H. Hansen, L. Munksgaard, P. Lund, and T. Kristensen. 2013. Estimation of grass intake on pasture for dairy cows using tightly and loosely mounted di-and tri-axial accelerometers combined with bite count. Comput. Electron. Agric. 99:227-235.

Penning, P. 1983. A technique to record automatically some aspects of grazing and ruminating behaviour in sheep. Grass Forage Sci. $38: 89-96$
Penning, P. D., and S. M. Rutter. 2004. Ingestive behaviour. Pages 1-191 in Herbage Intake Handbook. 2nd ed. P. D. Penning, ed. British Grassland Society, Maidenhead, UK.

Phillips, C. 2002. Cattle Behaviour and Welfare. 2nd ed. John Wiley \& Sons, Blackwell Science, Oxford, UK.

R Core Team. 2015. R: A language and environment for statistical computing. R Foundation for Statistical Computing, Vienna, Austria. Accessed Feb. 10, 2015. http://www.R-project.org/.

Rutter, S. M., R. A. Champion, and P. D. Penning. 1997. An automatic system to record foraging behaviour in free-ranging ruminants. Appl. Anim. Behav. Sci. 54:185-195.

Ruuska, S., S. Kajava, M. Mughal, N. Zehner, and J. Mononen. 2016. Validation of a pressure sensor-based system for measuring eating, rumination and drinking behaviour of dairy cattle. Appl. Anim. Behav. Sci. 174:19-23.

Scheibe, K. M., and C. Gromann. 2006. Application testing of a new three-dimensional acceleration measuring system with wireless data transfer (WAS) for behavior analysis. Behav. Res. Methods $38: 427-433$.

Soriani, N., E. Trevisi, and L. Calamari. 2012. Relationships between rumination time, metabolic conditions, and health status in dairy cows during the transition period. J. Anim. Sci. 90:4544-4554.

Ungar, E. D., and S. M. Rutter. 2006. Classifying cattle jaw movements: Comparing IGER Behaviour Recorder and acoustic techniques. Appl. Anim. Behav. Sci. 98:11-27.

Weary, D. M., J. M. Huzzey, and M. A. G. Von Keyserlingk. 2009. Board-invited review: Using behavior to predict and identify ill health in animals. J. Anim. Sci. 87:770-777.

Zehner, N., M. Hürlimann, and M. Hoch. 2014. User Guide RumiWatch Converter Version 0.7.3.2 and Higher. User Guide. Bennwil, Switzerland.

Zehner, N., J. J. Niederhauser, F. Nydegger, A. Grothmann, M. Keller, M. Hoch, A. Haeussermann, and M. Schick. 2012. Validation of a new health monitoring system (RumiWatch) for combined automatic measurement of rumination, feed intake, water intake and locomotion in dairy cows. Pages C-0438 in Proc. Int. Conf. Agric. Eng. CIGR-AgEng, Valencia, Spain. 